\title{
Staghorn Blood Clot
}

\author{
Hsin-Ming Lee ${ }^{1,3}$, Rheun-Chuan Lee ${ }^{2,3}$, Wu-Chang Yang ${ }^{1,3}$ and Chih-Yu Yang ${ }^{1,3}$
}

Key words: staghorn blood clot, clot anuria, obstructive uropathy, polycystic kidney disease, magnetic resonance imaging

(Intern Med 50: 2715, 2011)

(DOI: 10.2169/internalmedicine.50.6411)
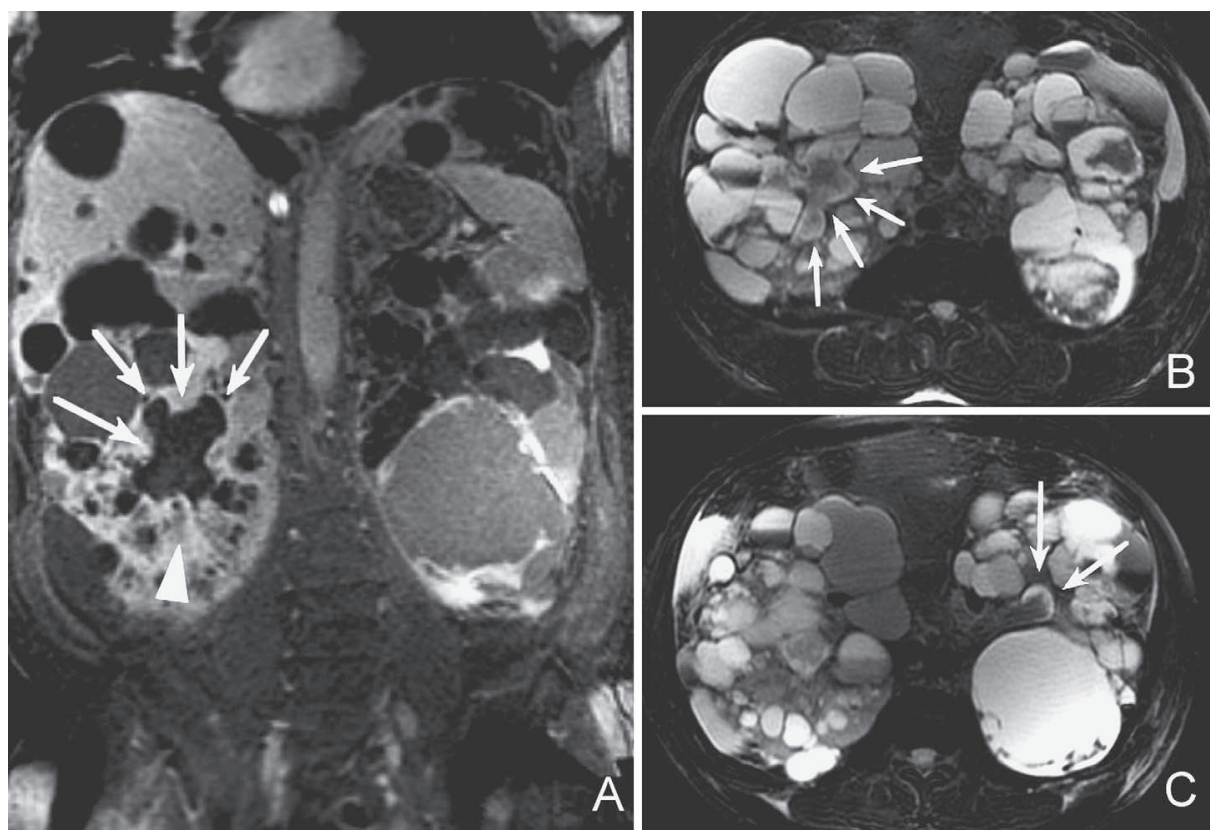

Picture.

A 61-year-old man with autosomal dominant polycystic kidney disease suffered from alternating anuria and polyuria resulting from cyst bleeding with clot formation in renal pelvis, a finding which could not be detected by ultrasonography. Subsequent magnetic resonance imaging revealed the right renal pelvis and major calyces were filled with staghorn-shaped blood clots in both coronal sections of $\mathrm{T}_{1}$-weighted image (Picture $\mathrm{A}$ ) and axial section of $\mathrm{T}_{2-}$ weighted image (Picture B). The left collecting system was also obstructed (Picture C). Alternating anuria and polyuria is an uncommon but classical manifestation of urinary tract obstruction, and it is usually caused by fluctuating accumulation and release of urine behind the obstructing lesion (1).
The term "staghorn blood clot" as first described by Ronchi et al (2), refers to a blood clot filling the collecting system and it results in obstructive uropathy.

The authors state that they have no Conflict of Interest (COI).

\section{References}

1. Lameire N, Hoste E. Reflections on the definition, classification, and diagnostic evaluation of acute renal failure. Curr Opin Crit Care 10: 468-475, 2004.

2. Ronchi F, Erembourg L, Rando C, Pricolo VE. Staghorn blood clot voided spontaneously from the urinary tract. Br J Urol 56: 337, 1984.

\footnotetext{
${ }^{1}$ Division of Nephrology, Department of Medicine, Taipei Veterans General Hospital, Taiwan, ${ }^{2}$ Department of Radiology, Taipei Veterans General Hospital, Taiwan and ${ }^{3}$ School of Medicine, National Yang-Ming University, Taiwan

Received for publication August 19, 2011; Accepted for publication August 23, 2011

Correspondence to Dr. Chih-Yu Yang, cyyang3@vghtpe.gov.tw

(C) 2011 The Japanese Society of Internal Medicine Journal Website: http://www.naika.or.jp/imindex.html
} 